\title{
Strategies for mining in highly burst-prone ground conditions at Vale Garson Mine
}

\author{
M. Yao Vale Limited, Canada \\ L. Moreau-Verlaan Vale Limited, Canada
}

\begin{abstract}
While mining at depth in \#1 Shear East orebody from 4700 Level to 5100 Level at Vale's Garson Mine in the Sudbury Basin, several major seismic events have occurred. The largest of these events recorded a magnitude of $3.1 \mathrm{Mn}$ (Nuttli), resulting in substantial damage to underground openings on multiple levels. Described within this paper are the findings from an extensive review of those major seismic events focusing on the determination of source mechanisms. Both strategic and tactical mitigation measures to withstand future seismic impact are presented in the paper.
\end{abstract}

Strategic measures include: developing an engineering geology model to identify all future high risk zones; undertaking numerical modelling to re-examine mining sequence; and investigating a mining layout change from transverse to longitudinal mining to gain a favourable stress environment. Tactical measures include: developing a methodology to determine the types of enhanced support required for high risk zones and standardising ground support practices when mining through various active dykes.

Additionally, numerical modelling indicates that the dyke pillar between \#1 Shear East and \#1 Shear West zones is subject to core failure at a certain mining stage. Also discussed within this paper are strategies to mitigate dynamic load-induced damage associated with the dyke pillar failure including field instrumentation and monitoring program (SMART cable bolts and MPBX).

\section{Introduction}

Garson Mine is wholly owned by Vale Limited. As shown in Figure 1, the mine is located in the Southeast quadrant of the Sudbury Basin, adjacent to the town of Garson, and within the city of Greater Sudbury.

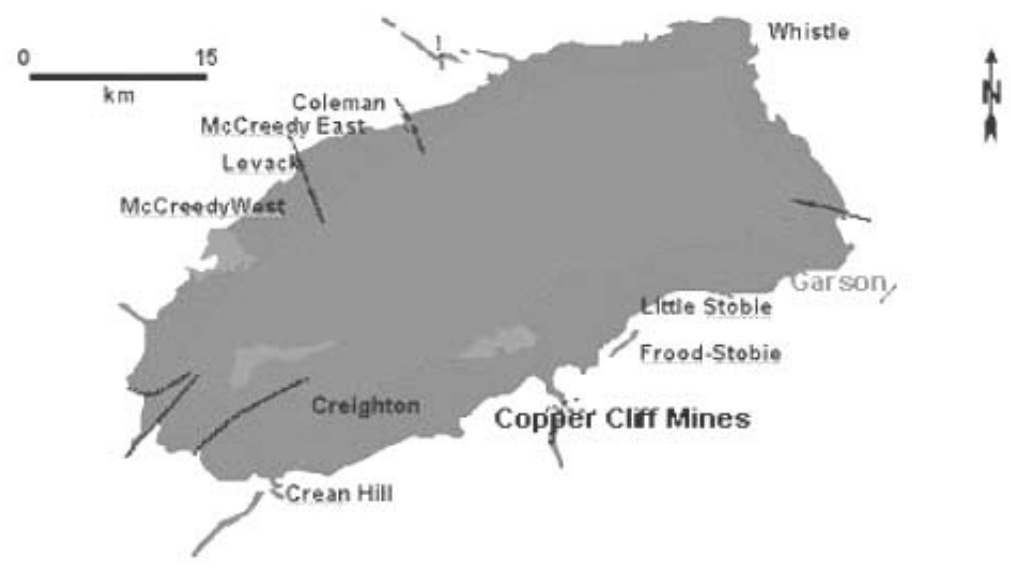

Figure 1 Location of Garson Mine in Sudbury Basin of Vale

The Garson Cu-Ni sulphides were originally discovered in 1891. In 1907, the first shaft was sunk at Garson Mine to a depth of $70 \mathrm{~m}$, and in 1908, production began at a rate of $200 \mathrm{t}$ per day. Today, with a shaft depth of 1,280 m, Garson Mine produces 2,300 t per day. 
In 2008, Garson Mine celebrated 100 years of production. Garson Mine has twice been the recipient of the National John T. Ryan Trophy, which represents the highest level of safety a mine can achieve, in 1945 and 2005.

The Garson Mine deposits consist of parallel, shear-hosted copper-nickel sulphides, offset by the intrusion of later stage dykes and possible late stage shearing. The footwall typically consists of the lower zone Norite of the Sudbury Igneous Complex (SIC) and metavolcanics (Greenstone/Metabasalt), while the hangingwall consists of metasediments. Figure 2 illustrates the geology present at Garson Mine.

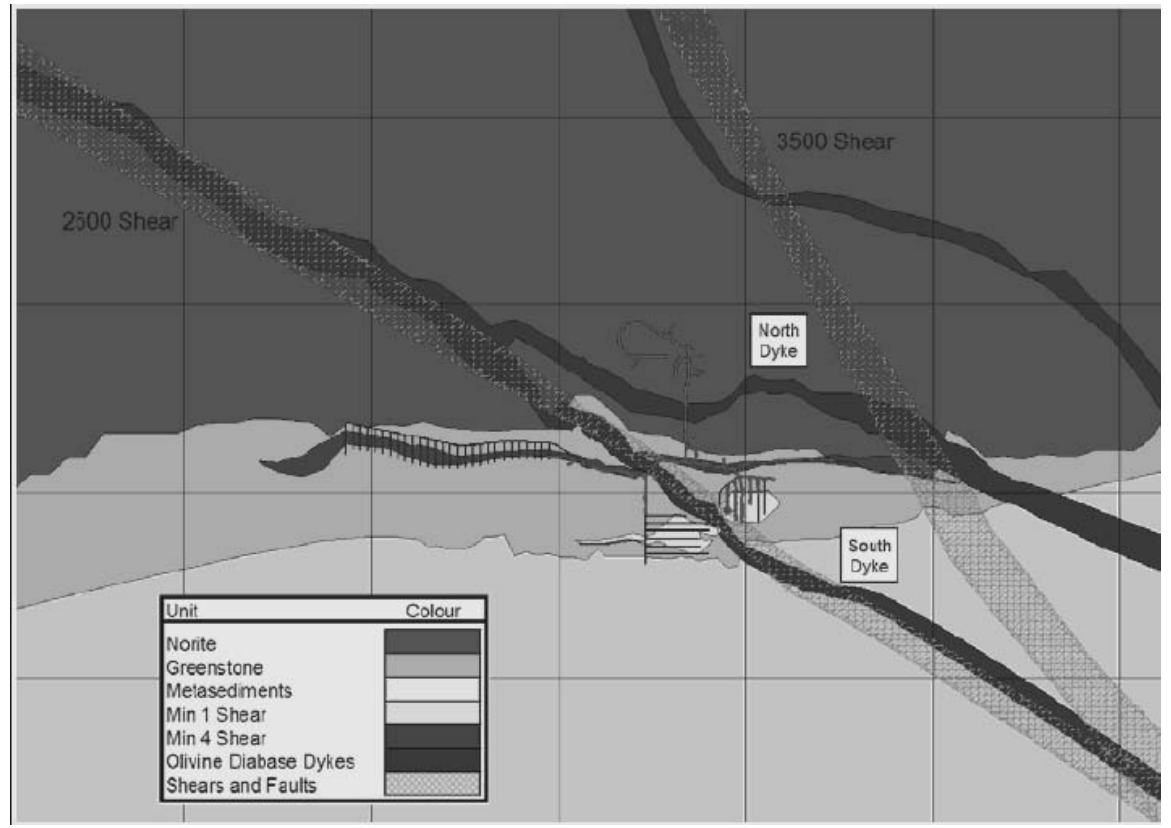

Figure 2 5000L plan view - geological structures at Garson Mine

Four main orebodies, numbered 1, 2, 3, and 4 shears have been recognised. The orebodies generally strike east-west and dip 75 degrees to the south. This paper will be focused on \#1 shear orebody only. It is the most dominant of the orebodies and is known to extend from surface to 1,700 m below surface. It is characterised by inclusion massive sulphide mineralisation with a sharp contact between the mineralised zones and the mostly barren footwall and hangingwall rocks. The strike length of the orebody gradually decreases from $600 \mathrm{~m}$ at 4000 Level to $120 \mathrm{~m}$ at 5600 Level. Widths along the orebody vary between 3.2 to $60 \mathrm{~m}$, with an average width of $10.6 \mathrm{~m}$. Mining is active within the \#1 Shear orebody between 3440 Level and 5100 Level. Currently, Garson Mine stope sizes are 12 to $15 \mathrm{~m}$ along strike, 15 to $21 \mathrm{~m}$ wide, and $30 \mathrm{~m}$ in height. Experience has shown that with this size of opening along the hangingwall and pastefill, very little problems occurred (minor hangingwall and pastefill slough).

An olivine diabase (OLDI) dyke with several offshoot dykes crosscuts the host rock and orebodies. The OLDI dykes average $30.5 \mathrm{~m} \mathrm{(100} \mathrm{ft)} \mathrm{in} \mathrm{width,} \mathrm{strike} \mathrm{northwest} \mathrm{and} \mathrm{dip} \mathrm{steeply} \mathrm{north.} \mathrm{The} \mathrm{OLDI} \mathrm{dyke} \mathrm{is} \mathrm{a}$ bifurcated dyke and can be broken into two units based on behaviour: (1) North limb; and (2) South limb, east of approximately $1800 \mathrm{E}$ section. The North dyke is a massive fine-grained diabase that is very stiff and brittle with $>1.5 \mathrm{~m}$ joint spacing and is prone to bursting. It is irregular in geometry and its distance from mining varies, but is roughly $90-120 \mathrm{~m}$ from mining except at the eastern limit of \#4 Shear. The South dyke, which splits and offsets the \#1 and \#4 Shear orebodies, has been influenced by late stage deformation. The reduction of burst prone behaviour in the South dyke as compared to the North dyke can likely be attributed to the presence of the shearing.

The metavolcanic and metasedimentary rocks of the Huronian, Stobie and McKim formations were overturned, folded and metamorphosed before the formation of the Sudbury Basin. The Penokean Orogeny was the first major period of deformation after the formation of the Sudbury Basin. The Orogeny is characterised by pervasive foliation, thrust faults, and folds. 
The Garson Mine orebodies are more deformed than any other orebodies of the Sudbury Basin. The foliation strikes east-west and dips steeply south. The orebodies have been elongated parallel to the foliation of the shear zones. Late-stage faults and fractures also deformed the orebodies. The Garson fault zone overprints the Penokean shear zones. The Garson fault is generally located along the norite-metavolcanic and metasediment contact and coincides with the \#1 Shear orebody. The fault zone is characterised by chloritefilled fractures/slips that vary in width from 25 to $300 \mathrm{~mm}$. The fault strikes east-west and dips steeply south. The fault extends from surface to below 5000 Level.

The late-stage extension fractures are 'joint-like' features that are commonly infilled with calcite, galena, marcasite, and sphalerite. Two major structural features of this type exist at Garson Mine, namely the 2500 shear and the 3500 shear. These fracture zones are approximately 15 to $20 \mathrm{~m}$ wide, strike approximately north-west and dip approximately 70 to 80 degrees east. Cumulative throw over these fracture zones has been measured up to $22 \mathrm{~m}$.

\section{Rockburst mechanisms}

Major rockbursts occurred in the last five years in \#1 shear east, as shown in Table 1, and they were analysed to gain a better understanding of rock mass behaviour resulting from seismicity associated with major identified structures.

Table 1 Major rockbursts occurred in \#1 shear east

\begin{tabular}{|c|c|c|c|c|}
\hline Date & $\begin{array}{l}\text { Magnitude } \\
\text { (Nuttli scale) }\end{array}$ & Tons Displaced & Location of Damage & Blasting Associated \\
\hline $\begin{array}{l}\text { 12/23/06 } \\
\text { @7:12am }\end{array}$ & 2.2 & $280 \mathrm{t}$ & First $3 \mathrm{x}$-cuts on $5000 \mathrm{~L}$ & 2901 and 2941 x-cuts@5:00am \\
\hline $\begin{array}{l}\text { 06/22/08 } \\
@ 8: 49 \mathrm{pm}\end{array}$ & 2.6 & $120 \mathrm{t}$ & $\begin{array}{l}100 \mathrm{t}-\text { walls in the access } \\
\text { drift on } 5000 \mathrm{~L} \\
20 \mathrm{t}-2881 \text { on } 4900 \mathrm{~L}\end{array}$ & $2881 \mathrm{~S}$ blasted on $06 / 12 / 06$ \\
\hline $\begin{array}{l}\text { 09/09/08 } \\
\text { @6:54pm }\end{array}$ & 2.9 & $700 \mathrm{t}$ & $\begin{array}{l}500 \mathrm{t} \text { - back and walls in } \\
2460 \mathrm{x} \text {-cut on } 4900 \mathrm{~L} \\
200 \mathrm{t}-\text { Diamond drill } \\
\text { station on } 5000 \mathrm{~L}\end{array}$ & $\begin{array}{l}2943 \mathrm{~S}(50-51) \text { crown, } 2901 \text { sill } \\
\text { on } 4900 \mathrm{~L}, 3101 \text { and } 3141 \text { sills } \\
\text { on } 5100 \mathrm{~L} @ 6: 50 \mathrm{pm}\end{array}$ \\
\hline $\begin{array}{l}\text { 12/05/08 } \\
@ 1: 36 \mathrm{pm}\end{array}$ & 3.1 & $400 \mathrm{t}$ & $\begin{array}{l}\text { All x-cuts on } 5100 \mathrm{~L} \\
\text { Mainly on walls, little } \\
\text { damage in the back }\end{array}$ & $\begin{array}{l}3101 \mathrm{~S}(50-51) \text { crown blasted } \\
\text { on } 12 / 01 / 08\end{array}$ \\
\hline
\end{tabular}

Although these events occurred at different mining stages, there are some similarities in terms of event locations, damage locations and ground support response to seismic events. Details of the most severe event with a magnitude of 3.1 Nuttli scale are given below.

\subsection{Detailed description of the largest event (Mn of 3.1) experienced to date}

On December 05, 2008, at 1:36 pm, an event occurred registering a magnitude of 3.1 Nuttli scale. The event was located in the No. 1 Shear East mining complex in the 2500 Structure Zone between North and South OLDI dyke at a depth of $1,550 \mathrm{~m}$, in the pillar $16 \mathrm{~m}$ west of $2901 \mathrm{x}$-Cut, as shown in Figure 3. Immediately after the event, Garson seismic communication protocol was followed to ensure that all personnel can safely proceed to the refuge stations. There were no injuries to underground personnel at the time of event. The event caused violent displacement of sill pillar walls in the cross-cuts of 3141, 3101, 3061, and 3021. Also, the pillar nose of 3021 displaced rock into the footwall drive, as shown in Figure 5. Most of the displaced rock came from the lower walls. The back was not damaged at all. In total, roughly 300-400 $t$ were displaced from sills. 
The 1 Shear East Sills support was as follows: back was supported with $2.4 \mathrm{~m}$ rebar on a $1.2 \times 1 \mathrm{~m}$ pattern with \#4 welded wire mesh (WWM). Walls were supported with $1.8 \mathrm{~m}$ rebar and FS46 friction sets on a $1.2 \times 1 \mathrm{~m}$ pattern with \#4 WWM. Backs were cable bolted with $6.1 \mathrm{~m}$ long double cable bolts up to rock/ore contact on a $2 \times 2 \mathrm{~m}$ pattern. Pillar noses were bolted and screened with \#4 WWM and FS46 friction sets and $1.8 \mathrm{~m}$ rebar to the floor plus a $60 \mathrm{~mm}$ layer of plain shotcrete followed by \#0 Gauge strapping installed with FS46 friction sets on upper, middle and lower wall.

The support in the back held up very well. No damage to screen or baggage was found in the back. All damage occurred to the walls. Majority of the walls were not bolted to the floor therefore the burst blew out the lower walls across the drift and the material from the upper walls fell around the bolts.

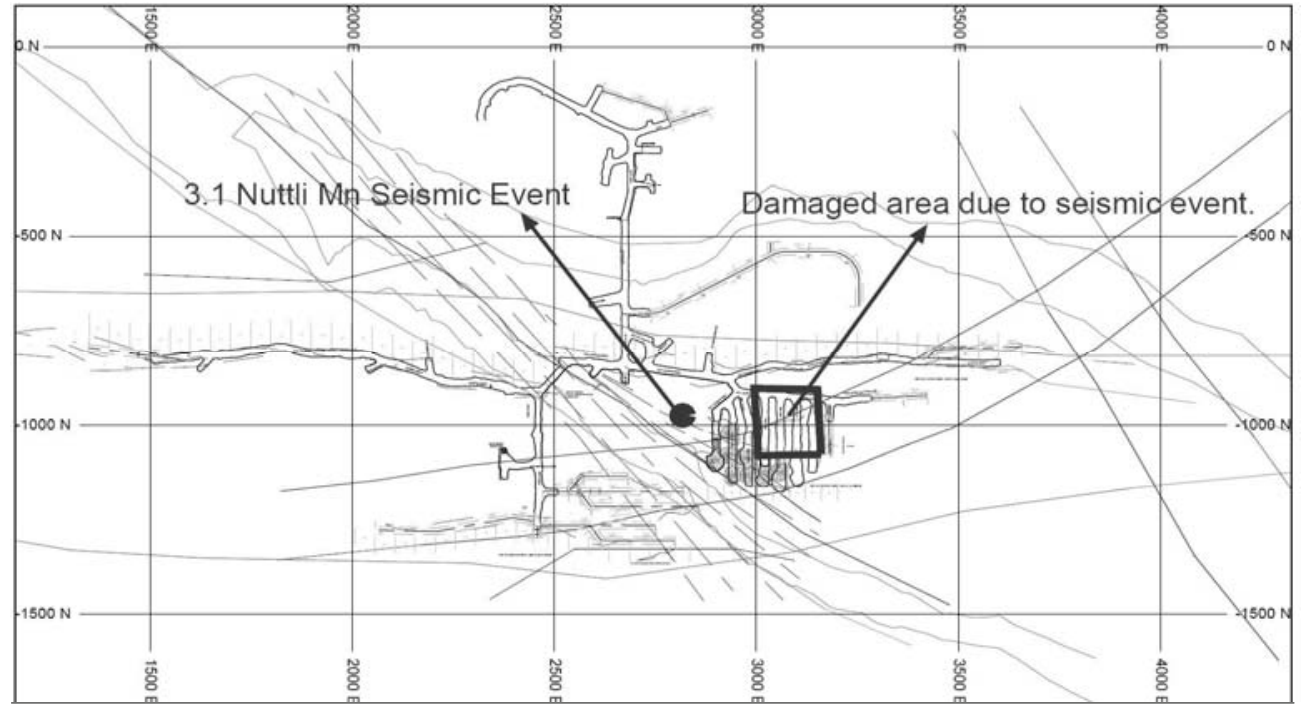

Figure 3 Rockburst from 3.1 Nuttli Magnitude seismic event at 5100 Level on 5 December 2008

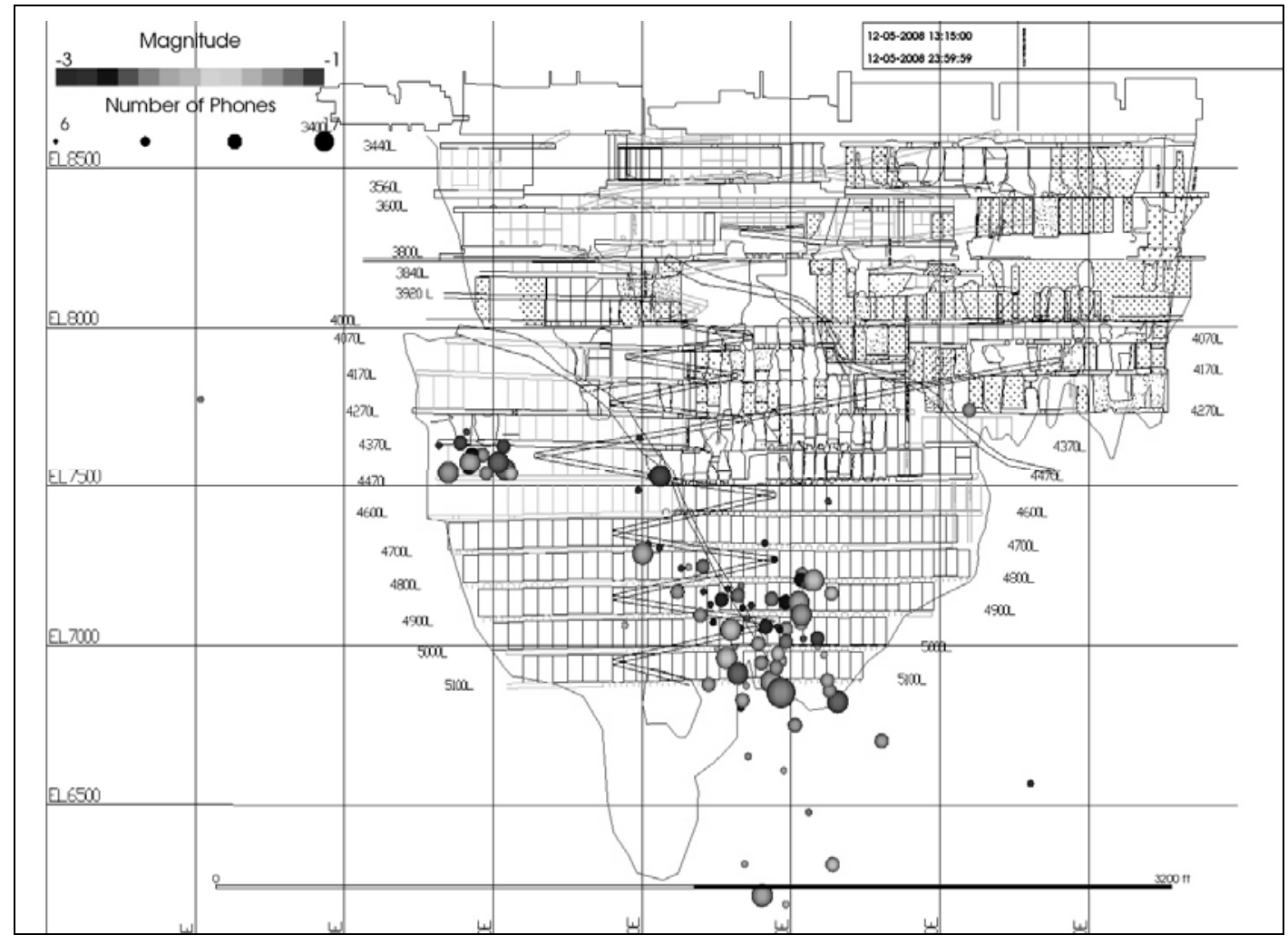

Figure 4 Seismicity at the mine on 5 December 2008 


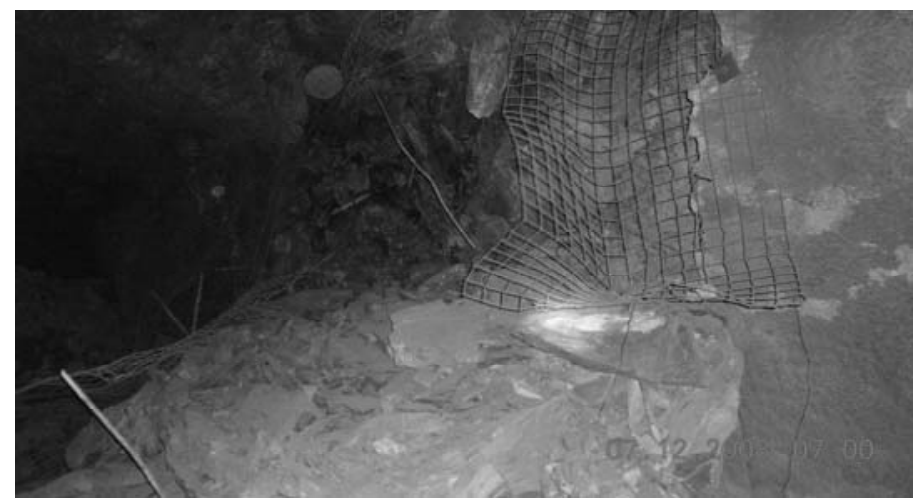

\section{Figure 5 Damage of pillar nose on 5100 Level}

\subsection{Key findings}

Key findings from the recent seismic events, as listed in Table 1, are summarised as follows:

- All these major seismic events are believed to be fault-slip induced rock mass shearing. This shear movement could occur along the well known active geological structures, including OLDI dyke and 2500 shear between \#1 shear East and West lenses.

- The majority of the damage (if not all of the damage) occurred outside of the ore zone in host rock.

- Damage occurred in the immediate area around the identified faults, i.e. potentially local poorer rock mass quality.

- Areas with enhanced support, such as cable bolts, performed better than the areas where only the standard support was installed.

- No dynamic support was installed in any of the damaged areas.

- It appears that event magnitude increases with the increase of extraction.

- The majority of the events occurred following either development or stope blasting.

- Time lapse between blasting and the occurrence of events varied from four minutes to more than four days.

- Two out of the four major events (50\%) occurred after stope crown blast. Crown blast with (vertical retreat mining) VRM allows large stress change in a short period.

- One major event (9 September 2008) occurred after a stope crown blast followed by three development blasts.

Historical rockburst information has also been analysed at the mine site. Trends associated with higher incidents of rockbursting include (Moreau-Verlaan and Bresee, 2009):

- Rockbursts at Garson are associated with diabase dykes, faults and fracture zones, such as 2500 shear. The locations of rockbursts at Garson Mine are strongly influenced by the geological and the structural environment.

- The in situ stress field in the vicinity of these structural features is anomalous; as indicated by the structural analysis, the high number of ground failures that occurred at these locations and the seismic monitoring. The rock mass in the vicinity of these structures is particularly sensitive to failure due to the stress changes caused by the mine openings. The failure type (strain, pillar, and slip) is influenced by the opening geometry and mechanical characteristics of the rockmass.

- Rockbursts occurred within massive non-foliated rock units such as diabase, fine-grained metavolcanics, and quartzite. These rock units are capable of storing strain energy resulting from tectonic and mining-induced stresses. 
- The olivine diabase appears to be particularly rockburst prone because of its moderate strength, and high Young's modulus. High stress environments occur in the sections of the diabase that are overprinted by the late stage fault and fracture zones.

\section{$3 \quad$ Mitigation plans to control seismic risks}

Although seismic risks cannot be totally eliminated in operations, application of sound strategic mine design, method and sequencing, enhanced dynamic ground support system as well as adequate re-entry protocol can be implemented to significantly reduce seismic risks. This paper will focus on the former, including mine design, mining method and sequencing and enhanced dynamic ground support system, but re-entry protocol, which is being successfully implemented in Vale's Sudbury operations using a combination of seismic watch (energy level) and events rate (Malek et al., 2006, 2008), will not be discussed in this paper.

After the occurrence of major events, mitigation plans must be established to ensure that the remaining ore bodies can be mined safely and efficiently. A few critical questions listed as below need to be answered:

- What types of enhanced dynamic support will likely be sufficient for the magnitude of potential future seismic events?

- Where should the enhanced dynamic support be installed relative to the active structures present in the mine?

- What are the strategic measures to be taken on mine design, mining method, sequencing and practices to reduce future seismic risks?

This paper will clearly demonstrate how these issues are addressed at Garson Mine.

\subsection{Enhanced dynamic support requirements}

\subsubsection{Where enhanced dynamic support is required?}

Although there are a wide variety of ground support elements, such as rockbolts, mesh/straps, shotcrete, cable bolts and modified cone bolts, some of these elements are specially designed to absorb energy when rockbursts occur. Even with dynamic support elements, each has different level of energy absorption. Generally speaking, dynamic support elements are much more expensive than the support elements designed for static loading. Golder Associates has been contracted to provide hazard maps to identify future high risk areas, where the appropriate dynamic support system is to be applied. A global approach, namely an engineering geology model (EGM) (Bewick, 2009c), has been developed by Golder Associates to determine where the dynamic enhanced support is required.

EGM was developed based on the review and collection of available relevant geomechanical, geologic and seismic data. The data included the exploration drillhole database, level mapping, seismic data, and interpreted faults zones. The data was compiled to assess:

- Location, orientation, and character of major structures (level mapping, interpreted fault zones, block model structural interpretation, etc.)

- Potential local stress orientation (level mapping, interpreted fault zones, seismic data, numerical back analysis, etc.)

- Areas of high stress concentration (core disking, seismicity, numerical modelling, etc.)

- The spatial and temporal repartition of the seismicity (seismic time links, mine sequencing, etc.)

- The relation between seismicity, geological structure and the mining activities (i.e. assessment of seismically active structures and spatial links/interactions).

Emphasis was placed on understanding and defining the major geological structures that potentially could concentrate seismicity and thus could potentially affect development and production mining. To gain this understanding, geomechanical and structural 3D models for the planned mining areas have been built (including data from rock mass classification and positions of known major geological structures), visualised 
in a three-dimensional (3D) environment, and projected using the 3D virtual reality (VR) lab facilities at Laurentian University. Figure 6 is 3D view of OLDI dyke with RQD distribution from EGM (Bewick et al., 2009a).

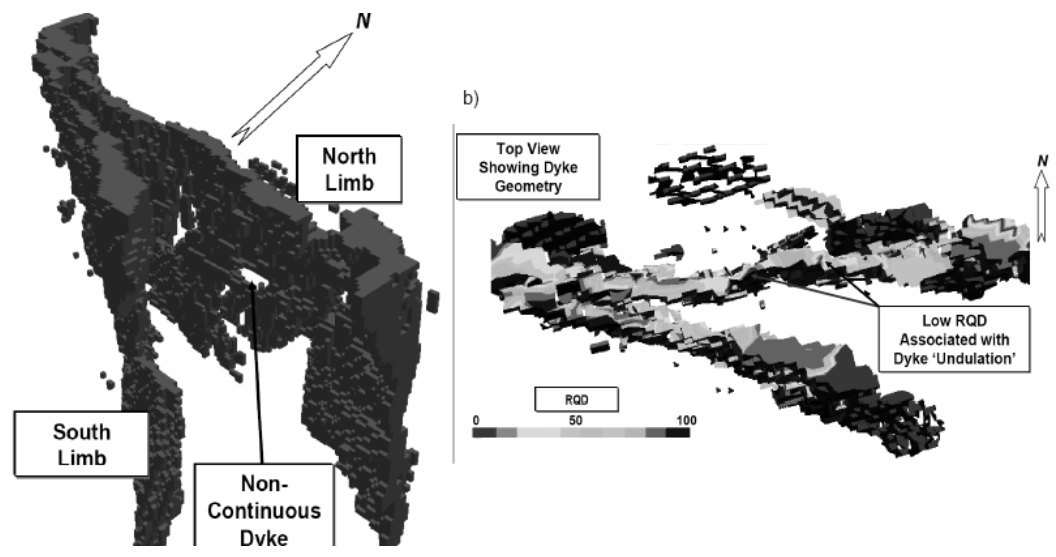

Figure 6 a) Olivine-diabase dyke geometry; b) top view of the dyke, colored by RQD (Bewick et al., 2009a)

Based on current seismic experience at Garson, the following assumptions were used to assess the areas needing the dynamic enhanced support and produce the hazard maps:

- One round $(3.6 \mathrm{~m})$ on either side of an excavation intersecting any seismically active structures on the level from EGM.

- $7.5 \mathrm{~m}$ vertical influence (above and below the level) of the structures on excavation stability. Flat structures generate a larger 'footprint' causing larger areas requiring dynamic enhanced support.

- Engineering judgment was used in some areas to extend the zone where the enhanced support is required. For example, due to close proximity to intersections.

Figure 7 illustrates the high risk areas identified on 5000 Level, which may require dynamic enhanced support, based on EGM.

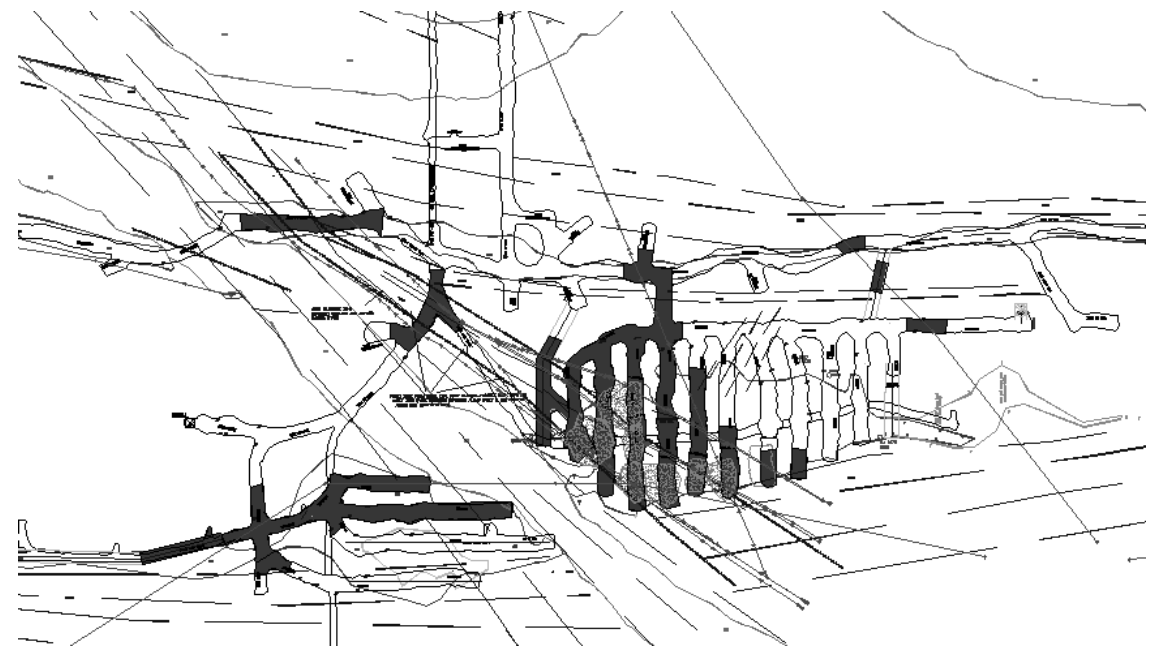

Figure 7 High risk areas identified on 5000 Level based on EGM

\subsubsection{What types of enhanced dynamic support are required?}

A five-step methodology is developed to determine what types of enhanced dynamic support are required to sustain future seismic events. 
The first step is to select the site, where the most severe damage occurred. Commonly, the largest seismic events take place in the proximity of this site.

The second step is to determine the ground motion level in terms of peak particle velocity (PPV), which can be generated at the drift surface when the largest events occurred. Kaiser et al. (1996) presents average predicted PPV as a function of distance and seismic event magnitude.

The third step is to calculate the total kinetic energy of any ejected block of rock, i.e. the demand on the support. The total energy can be determined by (Kaiser et al., 1996):

$$
\mathrm{Et}=1 / 2 \mathrm{~m} \mathrm{v}{ }_{\mathrm{e}}^{2}+\mathrm{qmgd}
$$

Where:

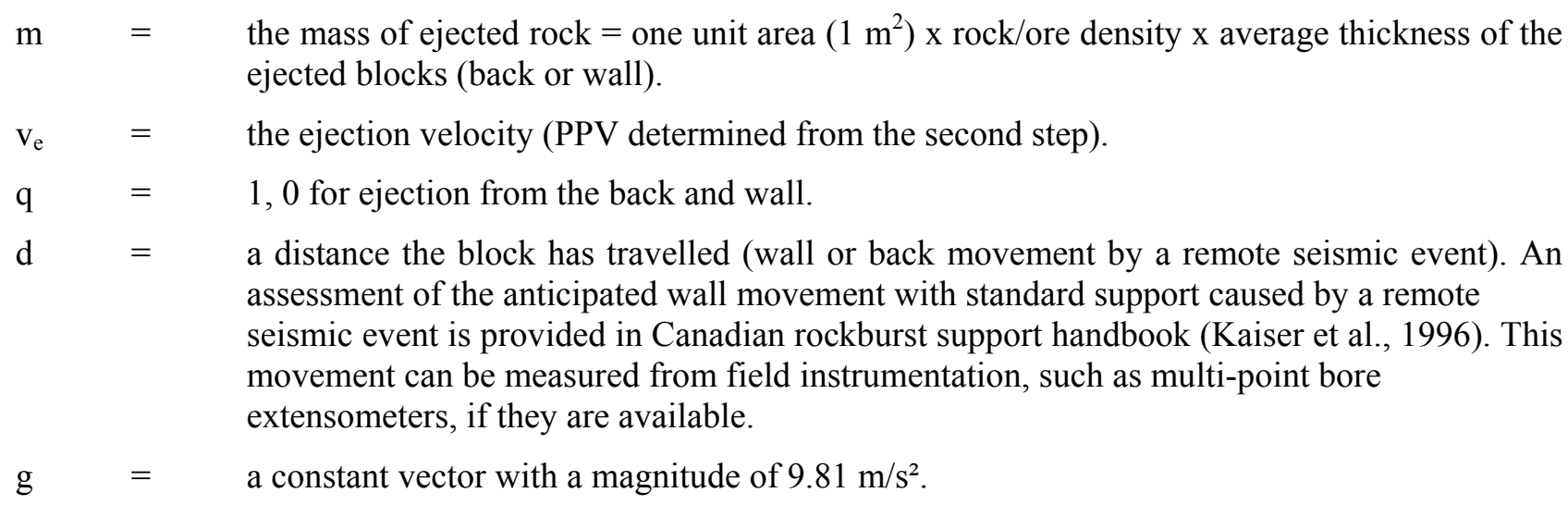

The fourth step is to determine the integrated support system consisting of various support elements (Table 2, Kaiser et al., 1996), which is currently being used at Vale Sudbury operations to achieve a support energy absorption capacity (energy absorption of any support element/bolt pattern) that exceeds the demand.

The fifth step is to calculate factor of safety (FS) = Capacity (from step four)/Demand (from step three). The required FS must be at least 1.3 and 1.5 respectively for temporary and permanent openings.

Table 2 Energy absorption (kJ) of various support elements (Kaiser et al., 1996)

\begin{tabular}{ll}
\hline Description* & Energy Absorption (Kj) \\
\hline $19 \mathrm{~mm}$ resin-grouted rebar & $1-4$ \\
Split set bolt (FS46) & $5-15$ \\
Yielding swellex bolt & $8-12$ \\
Yielding super swellex bolt & $18-25$ \\
$16 \mathrm{~mm}$ cone bolt & $10-25$ \\
$16 \mathrm{~mm}$ cable bolt & $2-6$ \\
$16 \mathrm{~mm}, 2.1 \mathrm{~m}$ debonded cable bolts & $6-10$ \\
\#4 gauge welded-wire mesh & $3-6 \mathrm{~m}^{2}$ \\
Shotcrete and welded-wire mesh & $3-5 \mathrm{x}$ mesh \\
\hline
\end{tabular}

*: Ground support elements being used at Vale Sudbury operations.

Based on the above analysis, following dynamic enhanced support is required to withstand future 3.0 Mn events in the proximity of mining areas:

1. Install $2.4 \mathrm{~m}$ rebars in the back and 2.1 m FS46 on walls with \#4 gauge screen @ 1.2 x 1 m pattern down to $300 \mathrm{~mm}$ from the floor.

2. Apply $75 \mathrm{~mm}$ thick plain shotcrete on top of the above.

3. Keep doing 1) and 2) for three rounds. 
4. Install $2.1 \mathrm{~m}$ long modified cone bolts (if ground is broken, cone bolts can be replaced with $2.1 \mathrm{~m}$ long standard yielding Swellex Mn12) with \#0 gauge mesh straps in one directions (longitudinally) @ $1.4 \mathrm{x}$ $1.4 \mathrm{~m}$ (four rows in the back and three rows on each wall).

5. Repeat 1) to 4) for next three rounds.

Cable bolts are required at intersections: $6 \mathrm{~m}$ long double cable bolts. One is fully bonded but the second cable has a $3.6 \mathrm{~m}$ de-bonded section.

The above methodology has also been successfully used at Vale's Copper Cliff North Mine to design dynamic enhanced support for the same purpose (Yao et al., 2009).

\subsection{Strategic measures to control future seismic risk}

Strategic measures on mine planning, including mining method, sequencing and practices, are discussed in this section to reduce future seismic risks.

\subsubsection{Mining method}

Current mining method calls for ore sill being laid out transversely. Due to the fact that majority of the active structures are located in the proximity of cross-cuts to the ore sills, severe damage occurred to all cross-cuts in host rock after major seismic events. The mine proposes a layout change for ore sills from transverse to longitudinal mining, as shown in Figure 8.

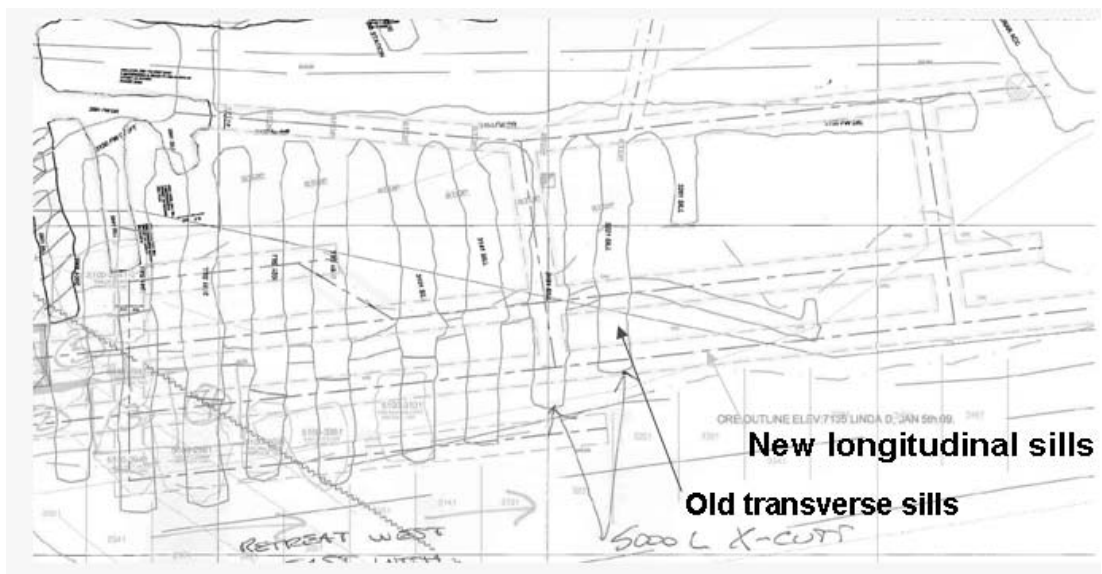

Figure 8 Change mining method from transverse to longitudinal mining

MAP 3D numerical modelling has been undertaken to compare stress distribution around drifts between the old and new layout (Bewick et al., 2009b). Tables 3 and 4 present the elastic properties and strengths, respectively, used in the numerical models for the main rock masses and dykes that occur between the 4600L and 5100L.

Table 3 Elastic properties for the OLDI dyke and rock mass

\begin{tabular}{lcc}
\hline Rock Type & Young's Modulus (GPa) & Poisson's Ratio \\
\hline Norite & 40 & 0.18 \\
North dyke (OLDI) & 100 & 0.20 \\
South dyke (OLDI) & 60 & 0.20 \\
Greenstone (GS) & 40 & 0.18 \\
Metasediments (MTSD) & 25 & 0.25 \\
Ore (massive sulphide) & 20 & 0.26 \\
Paste backfill & 0.1 & 0.30 \\
\hline
\end{tabular}


Table 4 Dyke and rock mass strengths

\begin{tabular}{lccc}
\hline Rock Type & UCS & \multicolumn{2}{c}{ Hoek and Brown, 1988 } \\
& (MPa) & mb & s \\
\hline Norite & 200 & 8.19 & 0.0622 \\
North dyke (OLDI) & 180 & 10.5 & 0.3292 \\
South dyke (OLDI) & 180 & 10.5 & 0.3292 \\
Greenstone (GS) & 200 & 8.19 & 0.0622 \\
Metasediments (MTSD) & 90 & 3.2 & 0.0039 \\
Ore (massive sulphide) & 90 & 10.3 & 0.0351 \\
\hline
\end{tabular}

Table 5 presents Sudbury Basin in situ stresses, where the major and intermediate principal stress components are considered to act in the horizontal plane while the minor principal stress component is vertical. Figures $9 \mathrm{a}$ to $9 \mathrm{~d}$ show plots (plan and section) of the in-ore-transverse $(5000 \mathrm{~L}$, old) and longitudinal (4900L, new) development layouts. The contours plotted are deviatoric stress, i.e. $\left(\left(\sigma_{1}-\sigma_{3}\right) / \mathrm{UCS}\right)$. In this criterion, the contour of 0.4 generally represents stress induced rock mass damage initiation and the contour of $>0.6$ generally represents yielded ground.

\section{Table 5 Sudbury Basin in situ stresses}

\begin{tabular}{llcc}
\hline Principal Stress Component & Magnitude $(\mathbf{p s i})$ & Trend $\left({ }^{\circ}\right)$ & Plunge $\left(^{\circ}\right)$ \\
\hline Major (horizontal), $\sigma_{1 \mathrm{H}}$ & $1575+550 \mathrm{~mm} *$ depth & 90 & 0 \\
Intermediate (horizontal), $\sigma_{2 \mathrm{H}}$ & $1260+440 \mathrm{~mm} *$ depth & 180 & 0 \\
Minor (vertical), $\sigma_{3 \mathrm{~V}}$ & $393 \mathrm{~mm} *$ depth & 0 & 90 \\
\hline
\end{tabular}

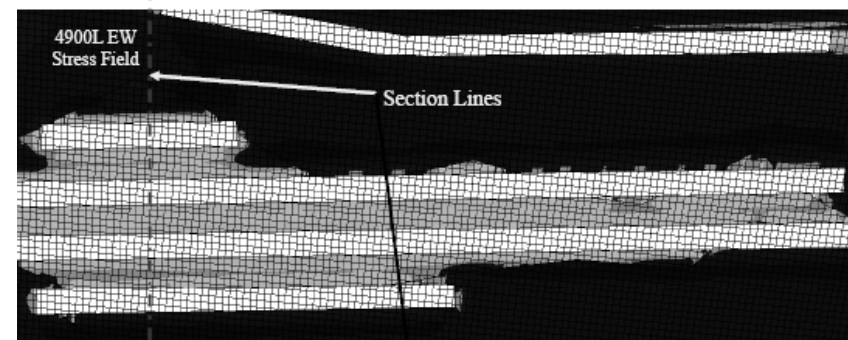

a)

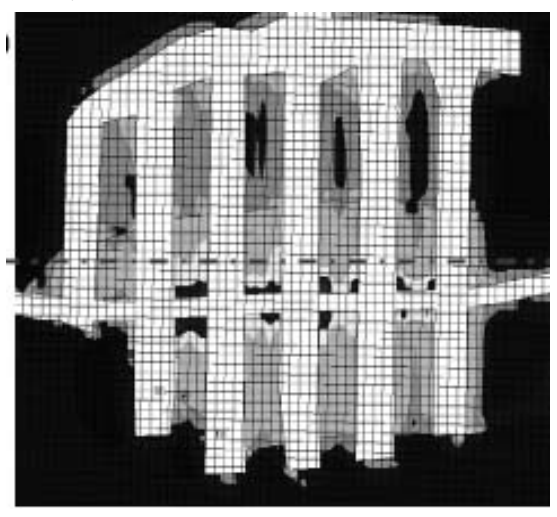

c)

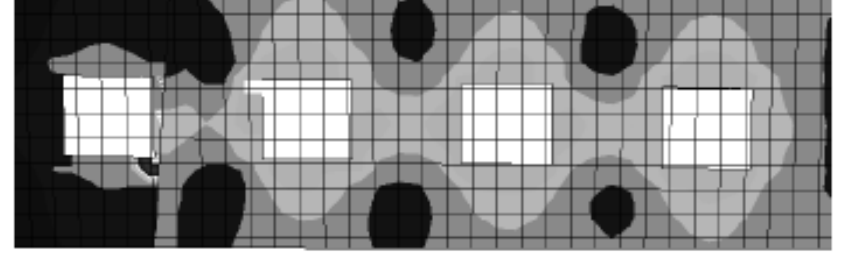

b)

Figure 9 Top - deviatoric stress with longitudinal mining on 4900 Level: a) plan view; b) section view. Bottom - deviatoric stress with transverse mining on 5000 Level: c) plan view; d) section view 
Based on the above numerical analysis, following conclusions can be made:

- Longitudinal mining (Figure 9a and 9b) provides much favourable stress condition both in the ore drifts and rib pillars between drifts compared with transverse mining (Figure 9c and 9d). This can be explained by the fact that longer axis of the ore sills is parallel to the major principal stress (east-west direction) with longitudinal ore sill layout.

- Although longitudinal drift layout is more favourable than transverse mining in terms of stress conditions, back and pillar noses must be monitored to ensure adequate support is provided.

- A total footage of rib pillars between drifts has been significantly reduced with longitudinal mining compared with transverse mining.

\subsubsection{Mining sequence}

Current practice of pillarless mining from west to east and mining away from OLDI dyke between east and west lens is to be continued, including west-end stopes from 4900 to $5000 \mathrm{~L}$.

\subsubsection{Mining practice and other measures}

If practical, crown blast should be taken without any other development/production blasts. This practice has been successfully implemented in other Vale Sudbury mines to control seismic risks. Other measures include: strategically install instrumented cable bolts and/or multi-point borehole extensometer (MPBX) to monitor ground movement and evaluate ground support performance in the central pillar between East and West \#1 shear orebodies etc., which has potential for major seismicity due to high stress concentration at a later stage of mining.

\section{Conclusions}

Analysis of major rockbursts that have occurred at Garson reveals that rockbursts are associated with diabase dykes, faults and fracture zones, such as 2500 shear. The locations of rockbursts at Garson Mine are strongly influenced by the geological and the structural environment.

By applying a methodical approach with the engineering and geology model (EGM), the Vale Garson Mine has been able to identify potentially burst prone areas and determine appropriate dynamic support requirements for those areas. Seismic risks have also been mitigated by strategic changes to mine design and planning, including:

- changing the mining method from transverse to longitudinal mining to gain favourable stress condition

- improving mining practice by limiting the blast size

- the introduction of field instrumentation to monitor ground movement and ground support effectiveness in high risk areas.

All these mitigation plans must be implemented to ensure that the remaining orebody can be mined safely and efficiently.

\section{Acknowledgements}

This paper would not be published without the support of Vale management at Garson Mine and Mines Technical Services/Support to all the ground control projects over the many years. Their dedication in enhancing work place safety and promoting worker awareness is greatly appreciated. The authors wish to thank particularly Dave Duncan (Mine Manager), Jim Willan (Manager, Mines Technical Support), Samantha Espley (Manager, Mines Technical Services) and Alex Henderson (General Manager, Mines Technology) for their permission to publish this paper. The authors are also grateful to Golder Associates for the great work undertaken at Garson mine during the past a few years. 


\section{References}

Bewick, R.P., Valley, B., Runnalls, S., Whitney, J. and Krynicki, Y. (2009a) Global Approach to Managing Deep Mining Hazards, in Proceedings 3rd CANUS Rock Mechanics Symposium, M. Diederichs and G. Grasselli (eds), Toronto, Canada.

Bewick, B., O’Donnell, D. and Castro, L. (2009b) MAP3D results for longitudinal drifting on 4900 and 4800 Levels, Submitted to Vale Inco.

Bewick, B. (2009c) Garson Mine Geomechanical Study, June 2009, submitted to Vale Inco, Canada.

Hoek, E. and Brown, E.T. (1988) The Hoek-Brown Failure Criterion - a 1988 Update, in Proceedings 15th Canadian Rock Mechanics Symposium, University of Toronto, Canada.

Kaiser, P.K., McCreath, D. and Tannant, D.D. (1996) Canadian Rockburst Support Handbook, Geomechanics Research Centre, Laurentian University, Canada.

Malek, F., Trifu, C., Suorineni, F.T., Espley, S. and Yao, M. (2008) Management of High Stress and Seismicity at Vale Inco Creighton Mine, in Proceedings 42nd US Rock Mechanics Symposium and 2nd U.S.-Canada Rock Mechanics Symposium, held in San Francisco.

Malek, F. and Leslie, I.S. (2006) Using seismic data for rockburst re-entry protocol at Inco's Copper Cliff North Mine, in Proceedings 41st U.S. Symposium on Rock Mechanics (USRM) at Golden Rocks.

Moreau-Verlaan, L. and Bresee, J. (2009) Garson Mine Design Package. Vale Internal Documentation.

Yao, M., Chinnasane, R. and Harding, D. (2009) Mitigation Plans for Mining in Highly Burst-Prone Ground Conditions at Vale Inco Copper Cliff North Mine, in Proceedings 3rd CANUS Rock Mechanics Symposium, Toronto, May 2009, M. Diederichs and G. Grasselli (eds). 